\title{
Modular, Step-Efficient Palladium-Catalyzed Cross-Coupling Strategy To Access C6-Heteroaryl 2-Aminopurine Ribonucleosides
}

\author{
Helena S. Buchanan, ${ }^{\dagger, \S}$ Steven M. Pauff, ${ }^{\dagger} \S$ Tilemachos D. Kosmidis, ${ }^{\dagger}$ Andrea Taladriz-Sender, ${ }^{\dagger}$
} Olivia I. Rutherford, ${ }^{\dagger}$ Marine Z. C. Hatit, ${ }^{\dagger}$ Sabine Fenner, ${ }^{\dagger}$ Allan J. B. Watson, ${ }^{\dagger}$ and Glenn A. Burley ${ }^{*},{ }^{\dagger}$

${ }^{\dagger}$ Department of Pure \& Applied Chemistry, University of Strathclyde, 295 Cathedral Street, Glasgow G1 1XL, U.K.

${ }^{\ddagger}$ GlaxoSmithKline, Medicines Research Centre, Gunnels Wood Road, Stevenage, Hertfordshire SG1 2NY, U.K.

Supporting Information

ABSTRACT: Two Pd-catalyzed methods to access 6-heteroaryl 2-aminopurine ribonucleosides from 6-chloroguanosine are described. First, Pd-132-catalyzed Suzuki-Miyaura crosscoupling using a series of boron substrates and 6-chloroguanosine forms 6-heteroaryl-2-aminopurines in a single step. The versatility of 6-chloroguanosine is further demonstrated using a modified Sonogashira coupling employing potassium iodide as an additive. Finally, the utility of the 6-alkynyl-2-aminopurine ribonucleoside as a dipolarophile in $[3+2]$ cycloadditions is presented, affording triazoles and isoxazoles when reacted with azide and isonitrile 1,3-dipoles, respectively.
$\mathrm{N}$ ucleoside analogues are essential molecules for both clinical and basic research. To date, there are over 30 nucleoside analogues approved for use as antiviral or cytotoxic agents, with almost $50 \%$ of these analogues containing modifications to the natural pyrimidine/purine base. ${ }^{1}$ Additionally, base-modified ribonucleosides offer considerable opportunities to enhance the efficacy and cellular uptake properties of therapeutic oligoribonucleotides. ${ }^{2,3}$ Apart from clinical applications, base-derivatized nucleoside analogues are important biotechnological tools for probing fundamental DNA and RNA biology ${ }^{4-6}$ and for synthetic biology applications. ${ }^{7-12}$ Consequently, there is a pressing need for the development of cost-effective synthetic routes that facilitate access to novel nucleoside building blocks.

The 6-position of purines is a prime modification site for many of these applications. ${ }^{13}$ Current methods have predominantly focused on C6-arylation of adenosine ribo- and deoxyribonucleosides. ${ }^{14-24}$ In contrast, efficient access to C6heteroaryl guanosines, ${ }^{25,26}$ especially protocols that utilize a cost-effective coupling partner, such as $\mathbf{1}$, are notably limited (Scheme 1). ${ }^{25-29}$ One key structural difference between adenosine and guanosine nucleobases that has the potential to have a significant impact on the success of Pd-catalyzed cross-couplings is the presence of the N2 exocyclic amine. Heterocycles containing exocyclic amines are traditionally challenging substrates for Suzuki-Miyaura cross-couplings, resulting in variable product yields and the need for the development of bespoke reaction conditions. ${ }^{30}$

Thus, a challenge in the nucleoside synthetic arena is to develop a general set of conditions to prepare 6-heteroaryl guanosines from cost-effective substrates, such as 1 . Previous mechanistic studies of Suzuki-Miyaura couplings with heteroaryl chlorides have shown that oxidative addition across
Scheme 1. Modular and Step-Efficient Access to 6-Heteroaryl Guanosine Analogues

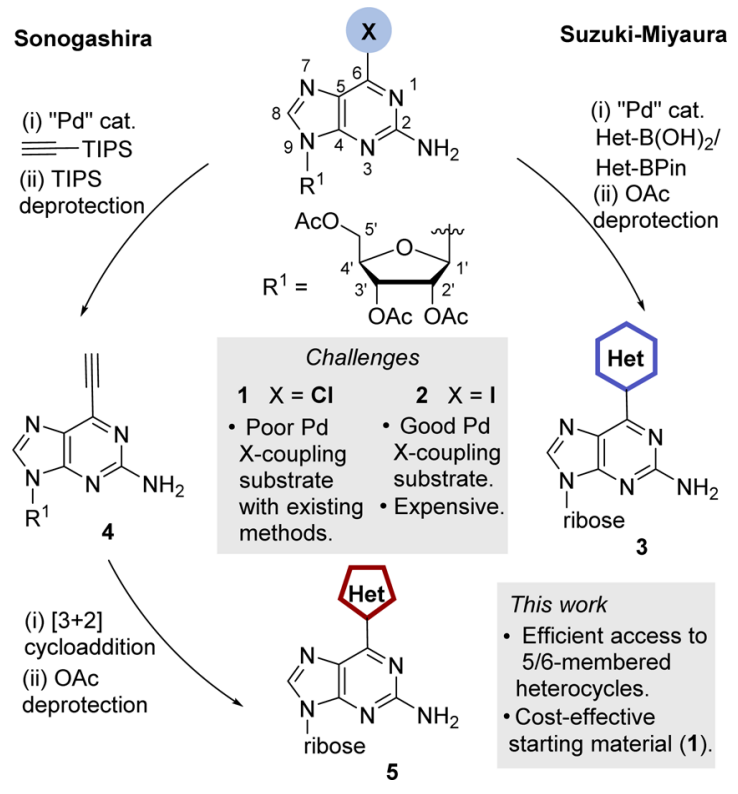

Het- $\mathrm{Cl}$ bonds can result in the formation of nonproductive and catalytically inactive $[\mathrm{Pd}-\mathrm{Cl}]$ intermediates. ${ }^{30}$ To circumvent this problem, current strategies that have been developed for the preparation of 6-heteroaryl guanosines require the use of the expensive 6-iodo-2-aminoguanosine (2) substrate, ${ }^{26,28,31}$ prepared from $\mathbf{1}$ via Finkelstein reaction. ${ }^{32}$

Received: May 27, 2017

Published: July 6, 2017 
Cross-coupling strategies such as Stille, ${ }^{33-35}$ Negishi, ${ }^{36-38}$ and other bespoke variants ${ }^{39,40}$ of these have been explored using both 1 and 2 . However, the toxicity associated with organotin reagents and the presence of a number of Lewis basic sites and electrophilic O-protecting groups have limited their broader utility.

Herein, we show that $\mathbf{1}$ can be used as a general coupling partner for the preparation of C6-heteroarylated guanosine analogues (3) via, for example, a Pd-132-catalyzed SuzukiMiyaura cross-coupling methodology (Scheme 1). Furthermore, we demonstrate the utility of $\mathbf{1}$ as a substrate for Sonogashira cross-couplings. ${ }^{14,18,41-43}$ Finally, we showcase the general utility of alkyne 4 as a dipolarophile in $[3+2]$ cycloadditions with azide and isonitrile 1,3-dipoles to prepare 6-heteroaryl guanosines (5) comprising 1,4-triazole and isoxazole units, respectively.

To establish optimal Suzuki-Miyaura coupling conditions, we used $\mathbf{1}$ and the boronic acid $\mathbf{6 a}$ as our exemplar reagent set. Exploration of reaction conditions recently developed for Suzuki-Miyaura cross-couplings with nucleoside heteroaryl organoborons and aryl iodides afforded product $7 \mathbf{a}$ in $58 \%$ yield (entry 1, Table 1). ${ }^{44}$ Altering the solvent had a minimal impact

Table 1. Optimization of Suzuki-Miyaura Coupling

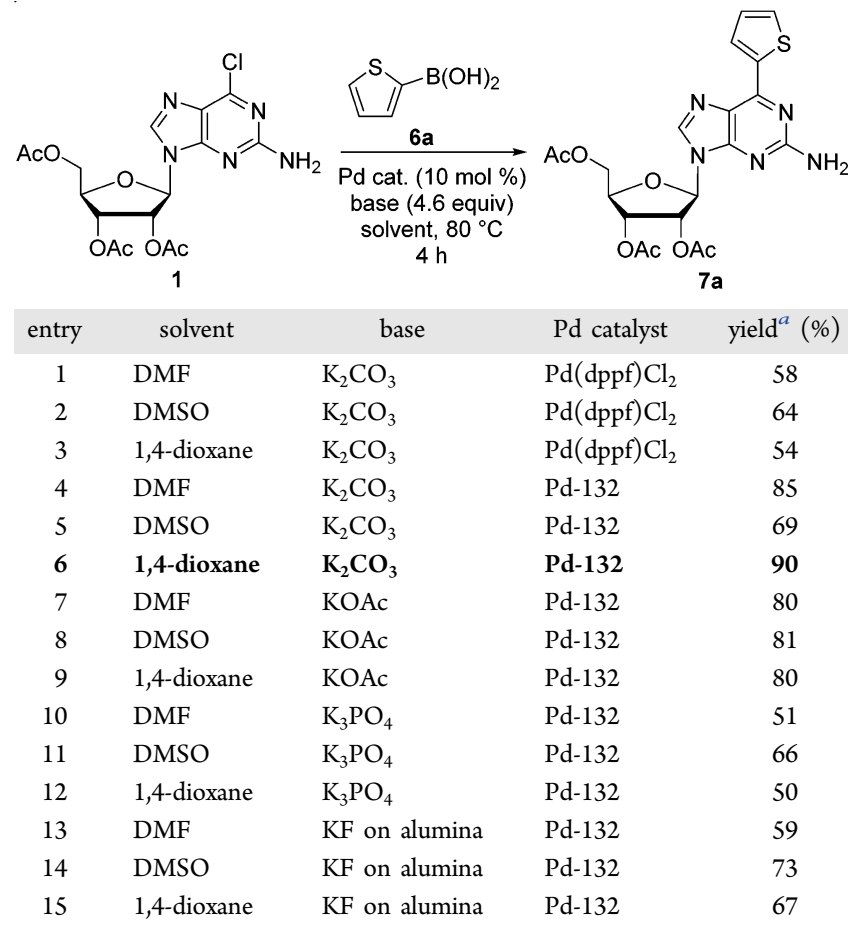

${ }^{a}$ Isolated yields.

on the yield of $7 \mathbf{a}$ using catalytic $\mathrm{Pd}(\mathrm{dppf}) \mathrm{Cl}_{2}$ and $\mathrm{K}_{2} \mathrm{CO}_{3}$ as the base (entries 2 and 3 , Table 1), whereas changing the $\mathrm{Pd}$ catalyst to Pd- $132^{45,46}$ resulted in a marked increase in the yield of $7 \mathbf{a}(85 \%$, entry 4 , Table 1$)$. After an extensive survey of base and solvent (entries 4-15, Table 1, Figure S1), the optimal set of conditions identified for this reaction were catalytic Pd-132 (10 mol \%) and $\mathrm{K}_{2} \mathrm{CO}_{3}$ in 1,4-dioxane (90\% isolated yield of 7a, entry 6, Table 1 ).

The utility of $\mathbf{1}$ as a general substrate for Suzuki-Miyaura couplings was then explored using a series of boronic acids and Bpin esters $\left(6 a-1\right.$, Scheme 2). Each of the $\mathrm{sp}^{2}-\mathrm{sp}^{2}$ couplings afforded the desired products $7 \mathbf{a}-\mathbf{g}, \mathbf{i}-\mathbf{k}$ in $57-97 \%$ yield,
Scheme 2. Scope of the Suzuki-Miyaura Cross-Coupling Using 1

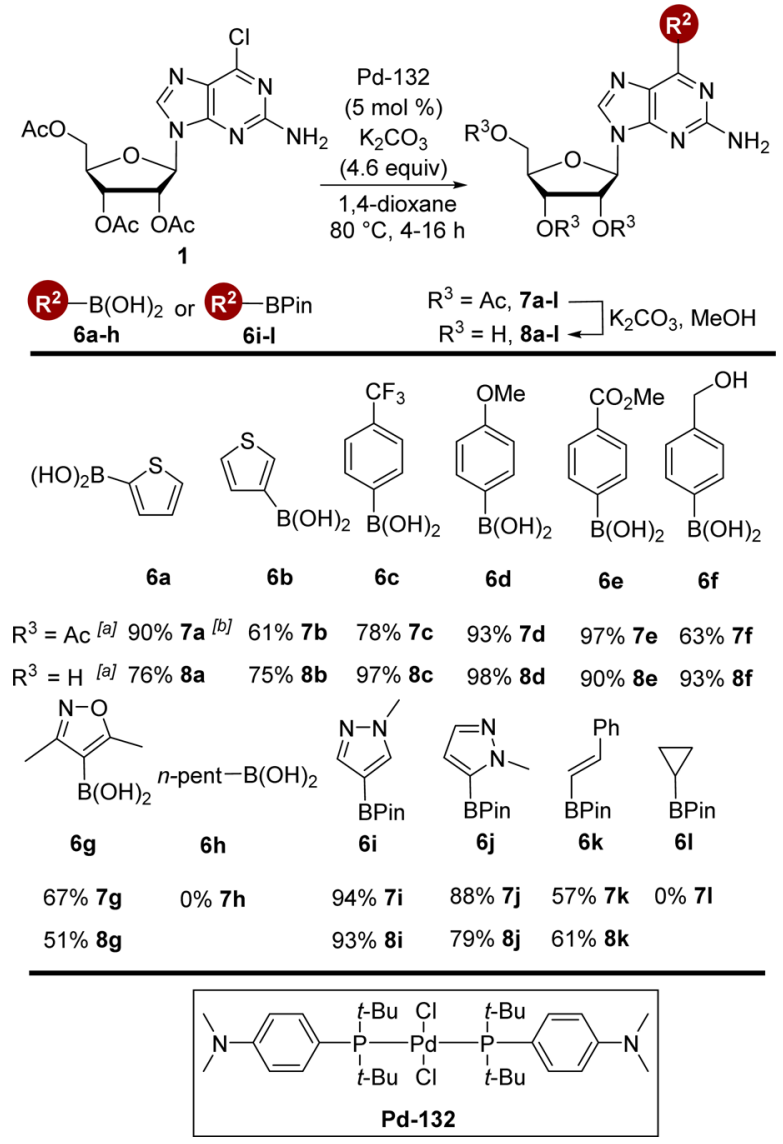

${ }^{a}$ Isolated yields. ${ }^{b} 92 \%$ yield on $1 \mathrm{mmol}$ scale.

which surveyed a range of electron-rich and electron-poor aryl and heteroaryl boron species. Unfortunately, $\mathrm{sp}^{3}-\mathrm{sp}^{2}$ couplings employing substrates $\mathbf{6 h}, \mathbf{l}$ resulted in the recovery of starting material from the crude mixture. The addition of $\mathrm{Ag}_{2} \mathrm{O}$ to the reaction with 61 again resulted in no reaction and no consumption of $1 .^{47}$ Acetyl deprotection of $7 \mathbf{a}-\mathbf{g}, \mathbf{i}-\mathbf{k}$ using $\mathrm{K}_{2} \mathrm{CO}_{3} / \mathrm{MeOH}$ afforded the corresponding free nucleosides $\mathbf{8} \mathbf{a}-\mathbf{g}, \mathbf{i}-\mathbf{k}$. To expand the diversity of heteroaryl substituents available for installation at the 6-position, we explored the utility of $\mathbf{1}$ in Sonogashira cross-couplings with TIPS-acetylene (9a, Figure 1).

A well-established phenomenon is that the Sonogashira reaction generally functions best when a (hetero)aryl iodide is used as a coupling partner. ${ }^{48}$ Indeed, coupling of acetylprotected 6-iodoguanosine (2) with 9a using catalytic $\mathrm{Pd}\left(\mathrm{PPh}_{3}\right) \mathrm{Cl}_{2} / \mathrm{CuI}$ produced 10a in $93 \%$ yield (Scheme $\left.\mathrm{S} 1\right){ }^{49}$ Under similar conditions, only $36 \%$ yield of 10a was obtained when 1 was used as the corresponding substrate (entry 1, Figure 1a). When $\mathrm{Pd}\left(\mathrm{PPh}_{3}\right) \mathrm{Cl}_{2}$ was replaced with $\mathrm{Pd}-132$ (i.e., 5\% Pd-132), the yield of 10a dropped to 21\% (Figure S2). We surmised that the addition of an iodide source to the reaction mixture would circumvent the need to prepare 2 . $^{48,50}$

A variety of iodide salts were evaluated using a benchmark set of conditions [i.e., $5 \mathrm{~mol} \%$ of $\mathrm{Pd}\left(\mathrm{PPh}_{3}\right) \mathrm{Cl}_{2}, 10 \mathrm{~mol} \%$ of $\mathrm{CuI}$, DIPEA, DMF; Figure 1a and Figure S2]. The addition of 1 equiv of alkali metal iodides (i.e., $\mathrm{NaI}, \mathrm{KI}, \mathrm{CsI}$ ) resulted in a significant increase in the yield of 10a; going from $36 \%$ (i.e., no iodide additive, entry 1$)$ to $76(\mathrm{NaI}), 86(\mathrm{KI})$, and $79 \%(\mathrm{CsI})$ 
(a)

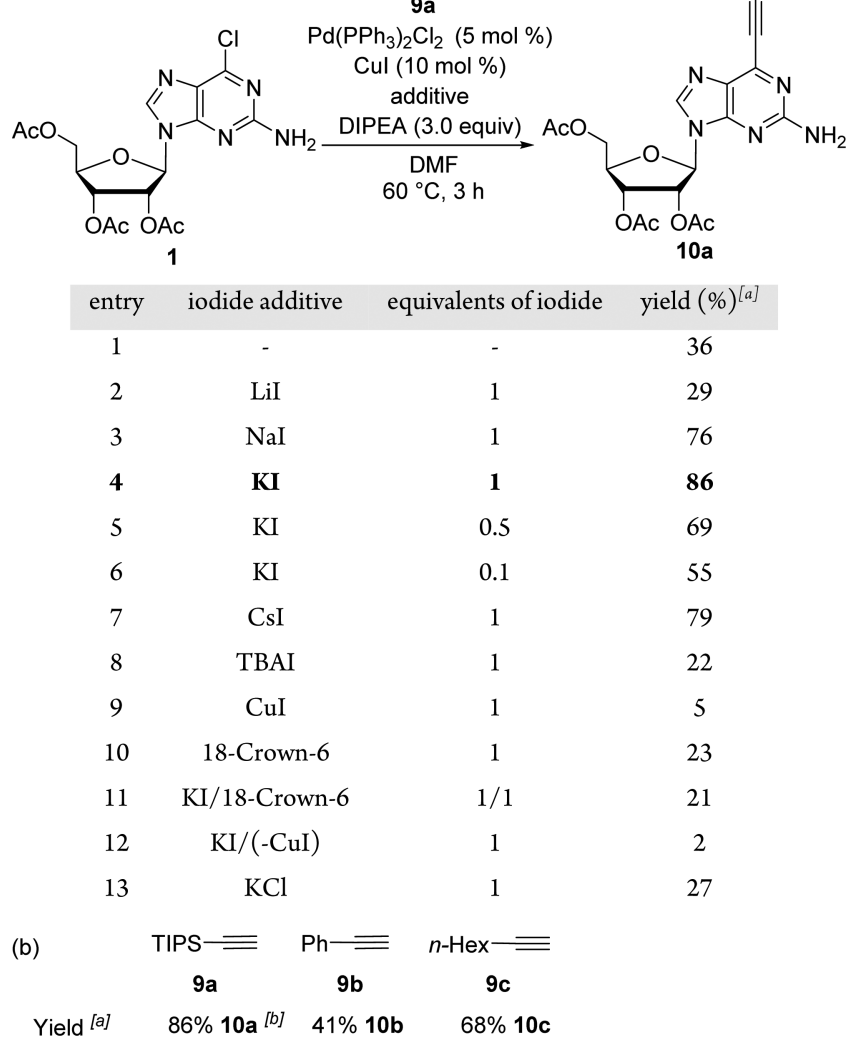

Figure 1. (a) Optimization of Sonogashira cross-coupling. (b) Substrate scope of Sonogashira cross-coupling of 1 using optimized conditions (entry 4). ${ }^{a}$ Isolated yields. ${ }^{b}$ Compound 10a obtained in $80 \%$ yield when conducted on a $1 \mathrm{mmol}$ scale. (entries 3, 4, and 7, Figure 1a). Decreasing the equivalents of $\mathrm{KI}$ to substoichiometric quantities resulted in a drop in the yield of 10a, which is indicative of the need for a stoichiometric iodide source (entries 4-6, Figure 1a; Figure S2). This was further confirmed when $\mathrm{KCl}$ replaced $\mathrm{KI}$, producing 10a in only $27 \%$ yield (entry 13, Figure 1a). These optimized conditions were then shown to be compatible with aromatic (9b) and aliphatic (9c) alkynes, producing 10b and 10c (Figure 1b).

We finally sought to explore the utility of alkyne 4 as a dipolarophile in $[3+2]$ cycloaddition reactions. TIPS deprotection of 10a using polymer-supported fluoride produced 4 in $78 \%$ yield (see Supporting Information). Using 4, a suite of isoxazole and triazole-substituted analogues $\mathbf{1 2} \mathbf{a}-\mathbf{e} / \mathbf{1 5} \mathbf{a}-\mathbf{c}$ were prepared. Both alkyl and aromatic oximes were tolerated, producing isoxazoles $12 \mathrm{a}-\mathrm{e}$ in $28-67 \%$ yield. Azides $14 a-c$ formed 1,4-triazoles $15 a-c$ in $21-83 \%$ yield under CuAAC conditions. Due to the nitrogen-rich and polar scaffold of these triazoles, the purification of these compounds required RP-HPLC. Finally, deprotection of the isoxazole and triazole series with $\mathrm{K}_{2} \mathrm{CO}_{3} / \mathrm{MeOH}$ afforded $13 \mathrm{a}-\mathbf{e}$ and $16 \mathrm{a}-\mathrm{c}$, respectively (Scheme 3).

In summary, we have developed modular, step-efficient methodologies for rapid access to a suite of 18 C6-heteroarylfunctionalized 2-aminopurine nucleosides from the costeffective 6-chloroguanosine precursor. Pd-132-catalyzed Suzuki-Miyaura coupling provides aryl and heteroaryl nucleosides in two steps from $\mathbf{1}$, whereas five-membered heteroaryl variants were prepared in four steps via a single alkyne intermediate 10a. We envisage that the utility of our synthetic approach will expand the development of guanosine-based analogues for therapeutic or synthetic biology applications.

Scheme 3. Modular Formation of Isoxazole and Triazole Nucleosides from 4

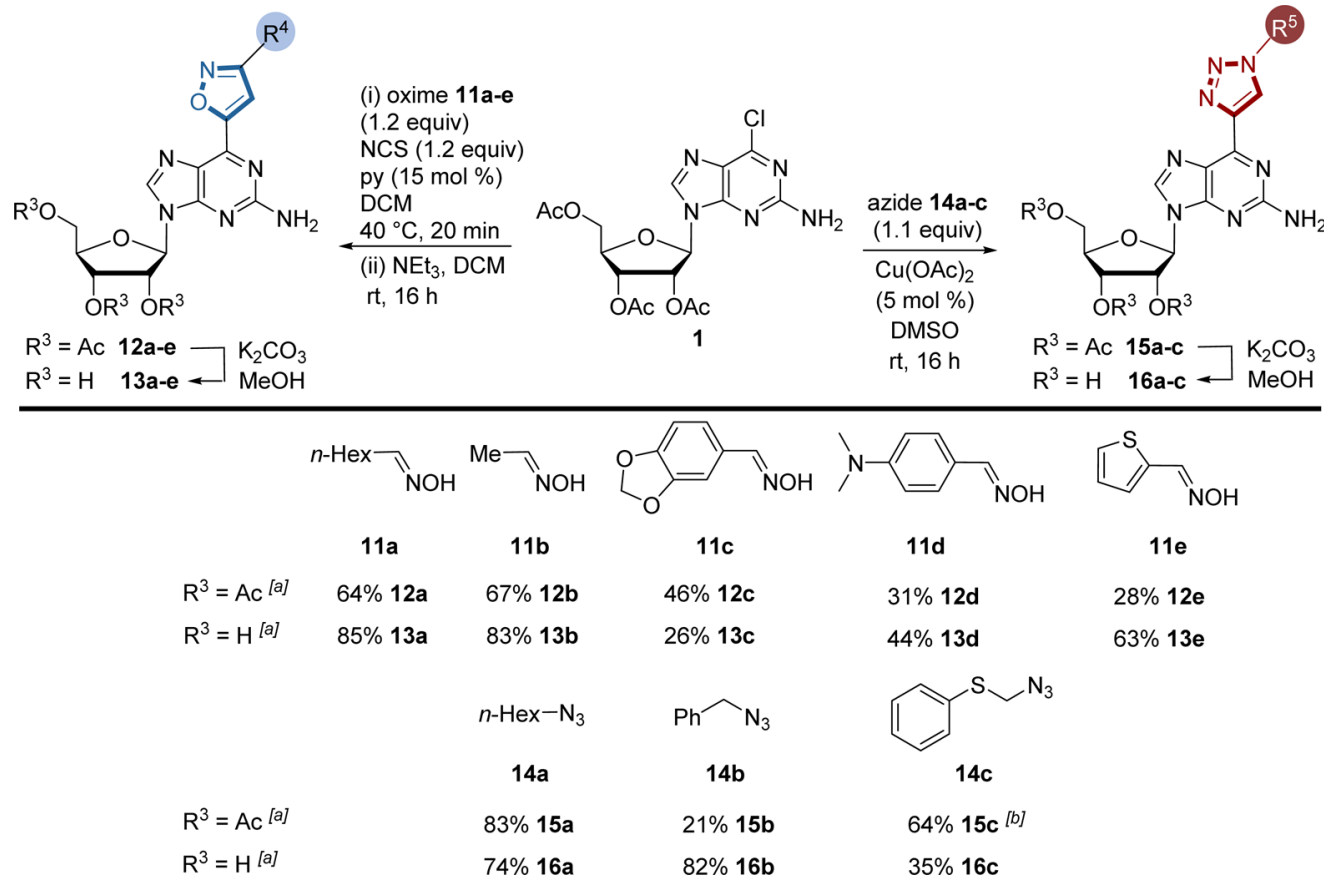

${ }^{a}$ Isolated yields. ${ }^{b} 55 \%$ yield on a $1 \mathrm{mmol}$ scale. 


\section{ASSOCIATED CONTENT}

\section{S Supporting Information}

The Supporting Information is available free of charge on the ACS Publications website at DOI: 10.1021/acs.orglett.7b01602.

Experimental procedures and characterization data for all compounds (PDF)

\section{AUTHOR INFORMATION}

\section{Corresponding Author}

*E-mail: glenn.burley@strath.ac.uk. ORCID $\odot$

Allan J. B. Watson: 0000-0002-1582-4286

Glenn A. Burley: 0000-0002-4896-113X

Author Contributions

${ }^{\S}$ H.S.B. and S.M.P. contributed equally. Notes

The authors declare no competing financial interest.

\section{ACKNOWLEDGMENTS}

This work was supported by an EPSRC-GSK industrial CASE studentship for H.B., a University studentship for T.D.K., and postdoctoral funding for S.P. by the Leverhulme Trust (RPG2014-313). We thank the EPSRC U.K. National Mass Spectrometry Facility at Swansea University for HRMS analyses of compounds.

\section{REFERENCES}

(1) Jordheim, L. P.; Durantel, D.; Zoulim, F.; Dumontet, C. Nat. Rev. Drug Discovery 2013, 12, 447.

(2) Warren, L.; Manos, P. D.; Ahfeldt, T.; Loh, Y.-H.; Li, H.; Lau, F.; Ebina, W.; Mandal, P. K.; Smith, Z. D.; Meissner, A.; Daley, G. Q.; Brack, A. S.; Collins, J. J.; Cowan, C.; Schlaeger, T. M.; Rossi, D. J. Cell Stem Cell 2010, 7, 618.

(3) Andries, O.; Mc Cafferty, S.; De Smedt, S. C.; Weiss, R.; Sanders, N. N.; Kitada, T. J. Controlled Release 2015, 217, 337.

(4) Strobel, S. A.; Shetty, K. Proc. Natl. Acad. Sci. U. S. A. 1997, 94, 2903.

(5) König, J.; Zarnack, K.; Luscombe, N. M.; Ule, J. Nat. Rev. Genet. 2012, 13, 77.

(6) Chaulk, S. G.; MacMillan, A. M. Nat. Protoc. 2007, 2, 1052.

(7) Reichenbach, L. F.; Sobri, A. A.; Zaccai, N. R.; Agnew, C.; Burton, N.; Eperon, L. P.; de Ornellas, S.; Eperon, I. C.; Brady, R. L.; Burley, G. A. Chem. 2016, 1, 946.

(8) Kimoto, M.; Mitsui, T.; Yokoyama, S.; Hirao, I. J. Am. Chem. Soc. 2010, 132, 4988.

(9) Hikida, Y.; Kimoto, M.; Yokoyama, S.; Hirao, I. Nat. Protoc. 2010, $5,1312$.

(10) Kimoto, M.; Kawai, R.; Mitsui, T.; Yokoyama, S.; Hirao, I. Nucleic Acids Res. 2009, 37, e14.

(11) Malyshev, D. A.; Dhami, K.; Lavergne, T.; Chen, T.; Dai, N.; Foster, J. M.; Correa, I. R., Jr.; Romesberg, F. E. Nature 2014, 509, 385.

(12) Zhang, Y.; Lamb, B. M.; Feldman, A. W.; Zhou, A. X.; Lavergne, T.; Li, L.; Romesberg, F. E. Proc. Natl. Acad. Sci. U. S. A. 2017, 114, 1317.

(13) Hocek, M.; Fojta, M. Chem. Soc. Rev. 2011, 40, 5802.

(14) Hocek, M.; Naus, P.; Pohl, R.; Votruba, I.; Furman, P. A.; Tharnish, P. M.; Otto, M. J. J. Med. Chem. 2005, 48, 5869.

(15) Taherpour, S.; Golubev, O.; Lonnberg, T. J. Org. Chem. 2014, 79, 8990.

(16) Amiable, C.; Paoletti, J.; Haouz, A.; Padilla, A.; Labesse, G.; Kaminski, P.-A.; Pochet, S. Eur. J. Med. Chem. 2014, 85, 418.
(17) Hassan, A. E. A.; Abou-Elkhair, R. A. I.; Riordan, J. M.; Allan, P. W.; Parker, W. B.; Khare, R.; Waud, W. R.; Montgomery, J. A.; Secrist, J. A., III. Eur. J. Med. Chem. 2012, 47, 167.

(18) Mathew, S. C.; By, Y.; Berthault, A.; Virolleaud, M.-A.; Carrega, L.; Chouraqui, G.; Commeiras, L.; Condo, J.; Attolini, M.; Gaudel-Siri, A.; Ruf, J.; Rodriguez, J.; Parrain, J.-L.; Guieu, R. Org. Biomol. Chem. 2010, 8, 3874.

(19) Heuberger, B. D.; Shin, D.; Switzer, C. Org. Lett. 2008, 10, 1091.

(20) Bambuch, V.; Pohl, R.; Hocek, M. Eur. J. Org. Chem. 2008, 2008, 2783.

(21) Bae, S.; Lakshman, M. K. J. Org. Chem. 2008, 73, 1311.

(22) Bae, S.; Lakshman, M. K. J. Am. Chem. Soc. 2007, 129, 782.

(23) Veliz, E. A.; Beal, P. A. J. Org. Chem. 2001, 66, 8592.

(24) Lakshman, M. K.; Hilmer, J. H.; Martin, J. Q.; Keeler, J. C.; Dinh, Y. Q. V.; Ngassa, F. N.; Russon, L. M. J. Am. Chem. Soc. 2001, $123,7779$.

(25) Lakshman, M. K.; Gunda, P.; Pradhan, P. J. Org. Chem. 2005, 70, 10329.

(26) Hocek, M.; Holy, A.; Votruba, I.; Dvorakova, H. J. Med. Chem. 2000, 43, 1817

(27) Lakshman, M. K.; Thomson, P. F.; Nuqui, M. A.; Hilmer, J. H.; Sevova, N.; Boggess, B. Org. Lett. 2002, 4, 1479.

(28) Qu, G. R.; Xin, P. Y.; Niu, H. Y.; Jin, X.; Guo, X. T.; Yang, X. N.; Guo, H. M. Tetrahedron 2011, 67, 9099.

(29) Lakshman, M. K.; Frank, J. Org. Biomol. Chem. 2009, 7, 2933.

(30) Düfert, M. A.; Billingsley, K. L.; Buchwald, S. L. J. Am. Chem. Soc. 2013, 135, 12877.

(31) Havelkova, M.; Dvorak, D.; Hocek, M. Synthesis 2001, 2001, 1704.

(32) Liu, J.; Janeba, Z.; Robins, M. J. Org. Lett. 2004, 6, 2917.

(33) Ren, H.; An, H.; Hatala, P. J.; Stevens, W. C., Jr.; Tao, J.; He, B. Beilstein J. Org. Chem. 2015, 11, 2509.

(34) James, D.; Escudier, J.-M.; Szlosek-Pinaud, M.; Fouquet, E. Molecules 2013, 18, 13654.

(35) Naus, P.; Perlikova, P.; Bourderioux, A.; Pohl, R.; Slavetinska, L.; Votruba, I.; Bahador, G.; Birkus, G.; Cihlar, T.; Hocek, M. Bioorg. Med. Chem. 2012, 20, 5202.

(36) Wang, D.-C.; Niu, H.-Y.; Qu, G.-R.; Liang, L.; Wei, X.-J.; Zhang, Y.; Guo, H.-M. Org. Biomol. Chem. 2011, 9, 7663.

(37) Gundersen, L.-L. Targets Heterocycl. Syst. 2008, 12, 85.

(38) Silhar, P.; Pohl, R.; Votruba, I.; Hocek, M. Collect. Czech. Chem. Commun. 2005, 70, 1669.

(39) Bhanu Prasad, A. S.; Stevenson, T. M.; Citineni, J. R.; Nyzam, V.; Knochel, P. Tetrahedron 1997, 53, 7237.

(40) Stevenson, T. M.; Prasad, A. S. B.; Citineni, J. R.; Knochel, P. Tetrahedron Lett. 1996, 37, 8375.

(41) Pu, X.; Li, H.; Colacot, T. J. J. Org. Chem. 2013, 78, 568.

(42) Yang, Y.; Chew, X.; Johannes, C. W.; Robins, E. G.; Jong, H.; Lim, Y. H. Eur. J. Org. Chem. 2014, 2014, 7184.

(43) Milburn, R. R.; Thiel, O. R.; Achmatowicz, M.; Wang, X.; Zigterman, J.; Bernard, C.; Colyer, J. T.; DiVirgilio, E.; Crockett, R.; Correll, T. L.; Nagapudi, K.; Ranganathan, K.; Hedley, S. J.; Allgeier, A.; Larsen, R. D. Org. Process Res. Dev. 2011, 15, 31.

(44) Klecka, M.; Pohl, R.; Klepetarova, B.; Hocek, M. Org. Biomol. Chem. 2009, 7, 866.

(45) Guram, A. S.; Wang, X.; Bunel, E. E.; Faul, M. M.; Larsen, R. D.; Martinelli, M. J. J. Org. Chem. 2007, 72, 5104.

(46) Guram, A. S.; King, A. O.; Allen, J. G.; Wang, X.; Schenkel, L. B.; Chan, J.; Bunel, E. E.; Faul, M. M.; Larsen, R. D.; Martinelli, M. J.; Reider, P. J. Org. Lett. 2006, 8, 1787.

(47) Zou, G.; Reddy, Y. K.; Falck, J. R. Tetrahedron Lett. 2001, 42, 7213.

(48) Chinchilla, R.; Nájera, C. Chem. Rev. 2007, 107, 874.

(49) Matsuda, A.; Shinozaki, M.; Yamaguchi, T.; Homma, H.; Nomoto, R.; Miyasaka, T.; Watanabe, Y.; Abiru, T. J. Med. Chem. 1992, 35, 241.

(50) Thathagar, M. B.; Rothenberg, G. Org. Biomol. Chem. 2006, 4, 111 